\title{
El nacimiento de Solidaridad Democrática Española en Francia y la participación de la Unión General de Trabajadores*
}

\author{
Juan Carlos Collado Jiménez \\ Fundación Francisco Largo Caballero
}

RESUMEN: Reorganizado el Partido Socialista y la Unión General de Trabajadores en Francia, en torno a la ciudad de Toulouse, en enero de 1945 nacía Solidaridad Democrática Española, una asociación pensada inicialmente para prestar ayuda y auxilio a los exiliados cercanos a sus organizaciones. Pero a los refugiados de la Guerra Civil acogidos en Francia se fueron uniendo todos los clandestinos que cruzaban la frontera porque huían del régimen de Franco o querían reagruparse con otros familiares exiliados. Tomando como punto de partida la situación en la que se encontraban los refugiados españoles en 1945, el presente trabajo pretende estudiar las causas que llevaron a la formación de Solidaridad, su financiación y ámbito de actuación, la función desarrollada por la asociación y las relaciones con las organizaciones españolas e internacionales hasta mediados de los años cincuenta. Las organizaciones socialistas precisaban un organismo con estos fines y este llegó a tener una cierta presencia y reconocimiento internacional con muy pocos recursos.

\section{PALABRAS CLAVE: organizaciones socialistas; exilio; Toulouse; refu- giados; clandestinos; solidaridad.}

\footnotetext{
* Este artículo se inscribe en las líneas de investigación abiertas en el seno del Proyecto «La trayectoria internacional del sindicalismo socialista español (1888-1986)», HAR201344849-P, dirigido por Manuela Aroca Mohedano y financiado por el Ministerio de Economía y Competitividad de España, Programa Estatal de Investigación Científica y Técnica de Excelencia, concedido a la Fundación Francisco Largo Caballero.

Para la elaboración de este texto se ha utilizado el Archivo de la Fundación Francisco Largo Caballero, Madrid (AFFLC) y de manera especial el fondo denominado Solidaridad Democrática Española, fondo que contiene toda la documentación orgánica de la organización socialista y ugetista hasta el año 1976.

1 jcarlos_collado@yahoo.es, ORCID iD: https://orcid.org/0000-0002-7894-1359 
The birth of Solidaridad Democrática Española in France and the involvement of the Unión General de Trabajadores

ABSTRACT: Once the Spanish Socialist Party and Unión General de Trabajadores (UGT) had reorganized in the vicinity of the French city of Toulouse, an association called Solidaridad Democrática Española was created in January 1945, initially to help exiles with ties to the above organizations. However people crossing the border clandestinely, either escaping from Franco's regime or seeking to be reunited with their exiled relatives, joined Civil War refugees already taken in France. Starting with the situation of these Spanish refugees in 1945, this paper considers the reasons for the creation of Solidaridad Democrática, how it was funded, the scope of its activities, the role played by the association and its relationship with Spanish and other international organizations until the midFifties. Socialist organizations needed a specific body to achieve their aims and the organization acquired a certain status and international recognition despite its scant resources.

KEY WORDS: Socialist organizations; exile; Toulouse; refugees; clandestine arrivals; solidarity.

CÓMO CITAR ESTE ARTICULO/CITATION: Collado Jiménez, Juan Carlos, «El nacimiento de Solidaridad Democrática Española en Francia y la participación de la Unión General de Trabajadores», Hispania, 78/259 (Madrid, 2018): 409-437. https://doi.org/ 10.3989/hispania.2018.011.

En el tiempo que duró la ocupación alemana de Francia durante la Segunda Guerra Mundial los núcleos socialistas del exilio más organizados en Europa se concentraban en el llamado Mediodía francés, con figuras tan representativas como Enrique de Francisco, Pascual Tomás, Arsenio Jimeno, Andrés Saborit, Trifón Gómez o Rodolfo Llopis². Pero no se caracterizaron los socialistas y ugetistas españoles exiliados por una intensa actividad en estos años. La emigración política se vio muy afectada por la Segunda Guerra Mundial en los países de acogida, fundamentalmente en Francia.

Las organizaciones socialistas españolas, tras la derrota republicana en la Guerra Civil, se encontraban, además, profundamente divididas y fragmentadas. El exilio masivo al que se vieron abocados sus militantes y dirigentes no contribuyó a cerrar heridas. Por el contrario, el Partido Socialista Obrero Español (PSOE), la Unión General de Trabajadores (UGT) y las Juventudes Socialistas (JJSS) escenificaron profundas diferencias durante los años de la Segunda Gran Guerra. Solamente a partir de 1944 comenzó una clarificación del panorama político socialista.

2 HEINE, 1983: 332.

Hispania, 2018, vol. LXXVIII, $\mathrm{n}^{\circ}$. 259, mayo-agosto, págs. 409-437, ISSN: 0018-2141, e-ISSN: 1988-8368 https://doi.org/10.3989/hispania.2018.011 
Si ponemos el acento en la Unión General de Trabajadores, como ya había pasado en el Congreso del Partido Socialista en Toulouse (24 y 25 de septiembre de 1944), la celebración del congreso encabezado en este caso por la facción ugetista del Comité Nacional, UGT-CN, entre los días 10 y 12 de noviembre de 1944, fue lo que posibilitó, a corto plazo, la unión de todas las tendencias del sindicato con la excepción de la corriente negrinista, que continuó teniendo personalidad durante algunos años más. La creación de una UGT socialista en el exilio, con la confluencia de besteiristas y caballeristas, permitió al sindicato iniciar un nuevo camino, compartido con el PSOE, que se extendió durante la práctica totalidad del periodo del destierro.

En ese marco de reconstrucción general de las organizaciones socialistas es en el que debemos situar el nacimiento de Solidaridad Democrática Española (SDE). Como pudieron constatar en primera persona Carlos y José Martínez Cobo, hijos de exiliados, residentes en Toulouse desde 1940 y afiliados a las organizaciones socialistas en 1952, el panorama de los exiliados en Francia era, en muchos casos, desolador. Personas mayores expulsadas de sus casas, mutilados, familias separadas, matrimonios rotos por la lejanía y el tiempo transcurrido desde el final de la guerra ${ }^{3} .$. Y no olvidemos que el PSOE y la UGT eran ilegales en Francia.

Con la celebración de los primeros congresos en el exilio del PSOE y de la UGT se había establecido un sello de 2 francos mensuales de la cuota con la finalidad de formar un fondo de solidaridad, sello que, junto con los ingresos obtenidos a través de donativos, fiestas o actos benéficos, sirvió durante unos meses para atender a los mutilados y enfermos, no exclusivamente militantes sino también familiares ${ }^{4}$. Pero esto no era suficiente para ocuparse de tantas personas necesitadas. La reorganización socialista en el exilio necesitaba de la creación de organismos de solidaridad para apoyar a los refugiados, por ello nacía en enero de 1945 Solidaridad Democrática Española. SDE era creada como asociación, en Toulouse, por la Unión General de Trabajadores y el Partido Socialista Obrero Español con la intervención de la Federación de las Juventudes Socialistas.

Para sortear las posibles trabas legales, el primer Comité Central de SDE estuvo integrado por socialistas franceses de Toulouse, que copaban de forma simbólica los cargos de la nueva organización (en la presidencia del Comité aparecía Raymond Badiou, alcalde socialista de Toulouse). Aunque era consecuencia de una reunión posterior cuando realmente se formalizaba, como ya funcionaba el organismo de manera efectiva, el 4 de mayo de 1945 se levantaba el Acta de Constitución Oficial. El 16 de octubre acordaron nombrar un Comité Central con las representaciones de las Comisiones Ejecutivas de

3 MARTÍNEZ COBO y MARTÍNEZ COBO, 1989: 279.

4 MARTIINEZ COBO y MARTÍNEZ COBO, 1989: 280. 
UGT y PSOE y de las JJSS para que actuara ya con independencia y de acuerdo con sus estatutos. Y, por fin, el primer Comité Central de SDE genuinamente español quedaba conformado con Arsenio Jimeno Velilla como presidente, Manuel Muiño Arroyo como secretario, Miguel Calzada San Miguel como tesorero y José Montero Rodelgo, Manuel Palacios y un representante de las Juventudes Socialistas en el exilio como vocales. Este Comité tomaba posesión de sus cargos el mismo día 16 de octubre de $1945^{5}$. Sin embargo, el siguiente paso en el aspecto formal no llegaría hasta casi dos años después. Solidaridad Democrática Española funcionaba legalmente desde 1945, pero el 2 de agosto de 1947 era legalizada al amparo de la Ley de asociaciones de 1901 por el Ministerio del Interior francés 6 .

Hasta el momento de la formación de Solidaridad hubo lugar a la reflexión y discusión entre los cuadros socialistas sobre lo que debía ser el organismo. ¿Cómo se va a organizar? ¿Cómo se va a financiar? ¿Quién va a tener la responsabilidad económica? Al final se optaba, como hemos visto, por establecer un Comité Central donde estaba representado un tripartito, tres representantes del PSOE en el exilio, tres de UGT y uno de las JJSS, que en realidad no era tal porque si hacemos un repaso a los integrantes de los diferentes comités generalmente se daban más puestos a $\mathrm{UGT}^{7}$. El cargo de presidente era para un miembro del PSOE y el de secretario para uno de UGT, y como el sindicato iba a ser el gestor económico el puesto de tesorero recaía también en el tesorero de la UGT.

El sindicato tenía más afiliados declarados de los que tenía el partido y, por supuesto, más que las Juventudes, por lo que, en palabras de Manuel Simón, miembro de las Ejecutivas en el exilio desde la segunda mitad de los años sesenta del siglo XX, secretario de Relaciones Internacionales de UGT ya en la transición y vocal de SDE entre 1968 y 1973, la Unión General de Trabajadores quedaba como la espina dorsal de la organización solidaria ${ }^{8}$. Con los datos en la mano observamos que UGT se expandió de una forma más rápida que el PSOE. En la Asamblea de Delegados de agosto de 1945 había 458 secciones y 82 grupos departamentales. Cuando se celebraba a fi-

5 Informe sobre la situación de los refugiados políticos elaborado por el Comité Central, Historia de Solidaridad Democrática Española, Toulouse, noviembre de 1951, AFFLC, 864-008: 2-3.

6 Certificado de legalización de SDE, París, 2-VIII-1947, AFFLC, 864-003.

7 Certificados del prefecto de Haute-Garonne declarando los cambios en la composición de los miembros del Comité Central desde 1947 hasta 1982, AFFLC, 864-010.

8 Entrevista a Manuel Simón Velasco realizada por Juan Carlos Collado Jiménez, Alcalá de Henares, 11 de abril de 2016, AFFLC, pendiente de catalogación. 
nales de septiembre de 1946 el II Congreso del sindicato habían aumentado a 466 las secciones y a 90 los grupos departamentales de UGT ${ }^{9}$.

La configuración directiva de SDE se repetía en Francia en los departamentos - equivalentes a nuestras provincias - , y en las distintas secciones integrantes de los grupos departamentales. Cada sección local tenía la obligación de crear su delegación de SDE y periódicamente se procedía a renovar en las mismas los cargos, presidente, secretario, tesorero y vocales, de la misma manera que se hacía en el Comité Central de Toulouse. Y este organismo se extendió y consolidó fundamentalmente en Francia, de forma paralela a los grupos departamentales y secciones del sindicato y del partido que se fueron creando. Cada familia política socialista debía tener sus estructuras para prestar este tipo de ayuda. El problema a la hora de configurar los comités era que las JJSS no existían reorganizadas en todos los lugares en los que sí se habían formado el PSOE y UGT, por lo que no siempre podían aportar miembros al tripartito.

Los ingresos de SDE procedían de 10 francos al mes extraídos de la cuota que pagaba cada afiliado a la Unión General de Trabajadores en el exilio (5 iban a parar a la caja del Comité Central y los otros cinco se destinaban a las necesidades de cada comité departamental), y de las aportaciones voluntarias de los propios afiliados, de entidades y particulares ${ }^{10}$. Aunque SDE no tenía afiliados individuales sino que lo eran en bloque todos los militantes que pertenecían al PSOE, UGT y las JJSS, si admitía socios honorarios protectores, entendidos como tales todos los que hacían donativos o ayudaban de alguna manera a la organización.

¿A qué personas iban dirigidas las ayudas? ¿Qué tipo de asistencia prestaba SDE? Lo hemos adelantado en parte. De conformidad con los primeros estatutos de 1945, el mismo día de su constitución se aprobaban los estatutos de la asociación ${ }^{11}$, Solidaridad quería encargarse del auxilio de los españoles pertenecientes a las organizaciones socialistas que se encontraban imposibilitados físicamente para obtener el sustento, enfermos, ancianos o mutilados. El auxilio solidario podía llegar igualmente a las viudas, hijos, padres y demás

9 MARTÍNEZ COBO y MARTÍNEZ COBO, 1989: 262. La unidad básica del sindicato se configuraba en torno a la sección, de modo que todos los afiliados de una villa, pueblo o ciudad pertenecían a la misma sección, y todas las secciones del departamento geográfico de referencia quedaban encuadradas en un grupo departamental. El grupo departamental era la unidad de la organización que vinculaba a sus secciones sindicales con la Comisión Ejecutiva de UGT. TCACH y REYES, 1986: 98-99.

10 Informe sobre la situación de los refugiados políticos elaborado por el Comité Central, Historia de Solidaridad Democrática Española, Toulouse, noviembre de 1951, AFFLC, 864-008: 3.

11 Acta de la Asamblea General Constituyente, 4-I-1945, AFFLC, 963-001. 
familiares de «antiguos compañeros ugetistas y socialistas» exiliados o a los que hubieran sufrido prisión o persecución ${ }^{12}$.

Había necesidad de crear un organismo de solidaridad pensando en los refugiados que se encontraban en dificultades laborales, administrativas, de salud e incluso de indigencia en algunos casos, pero enseguida los beneficios se extendieron igualmente a los afines que llegaban huidos desde España a partir de 1945 y entraban en Francia de manera clandestina. Estos nuevos desplazados se unieron al exilio republicano de 1939. Y este organismo atendió también, por humanidad, a muchos conocidos de militantes o a personas en situación de precariedad que no eran socialistas.

El Comité Central, con la colaboración de las organizaciones internacionales de solidaridad, especialmente francesas, conseguía ayudas individuales para afiliados enfermos, ingresos en centros de reposo o en otros establecimientos benéficos; y los distintos comités departamentales obtenían asistencia médica gratuita, ingreso en hospitales y otros beneficios ${ }^{13}$. Las ayudas podían ser también para pagar el alquiler de buhardillas o para la alimentación más básica, pasando por la entrega de medicamentos, ropas o unas gafas.

Además de procurar apoyo económico o material a los damnificados, Solidaridad también extendía avales a los militantes evadidos de España, necesarios para obtener los certificados de refugiados, o les proporcionaba trabajo. Y localizaba a familiares separados por el exilio. Muy importante la labor desarrollada por SDE para conocer el paradero de parientes que se habían dispersado después de la guerra.

La ficha del damnificado era la base del expediente iniciado por el Comité Central con las peticiones de asistencia. Los afectados se dirigían a Solidaridad Democrática Española por la delicada condición en la que se encontraban en Francia, muchas veces enfermos y sin medios para la subsistencia. Era preciso que estuviesen registradas todas las ayudas percibidas por el damnificado porque también había que rendir cuentas a las organizaciones cuando estas eran indirectas, de ahí que aparezcan anotadas en las fichas todas las relaciones establecidas por SDE con los organismos solidarios franceses e internacionales, independientes o de tendencias políticas concretas ${ }^{14}$.

12 Los estatutos eran editados en francés y en castellano: Estatutos aprobados, Toulouse, 4-III-1945, AFFLC, 864-001.

13 Informe sobre la situación de los refugiados políticos elaborado por el Comité Central, Historia de Solidaridad Democrática Española, Toulouse, noviembre de 1951, AFFLC, 864-008: 4.

14 Toda esta documentación pertenece al fondo Solidaridad Democrática Española, Expedientes de damnificados, AFFLC, 879 a 931. Expedientes de Refugiados Políticos, AFFLC, 933 a 962 y 964 . Censos, AFFLC, 866 a 870 y 971. 
Las ayudas a los damnificados no solamente llegaron, por tanto, por los recursos propios sino también, y sobre todo con el paso de los primeros años, gracias a los diferentes auxilios procedentes de organismos solidarios que aportaban dinero, víveres, ropa, medicamentos, organizaban colonias infantiles o facilitaban el acceso de los hijos de los militantes a becas de estudio.

Los hermanos Cobo destacan en sus trabajos que entre estos organismos estaban la Cruz Roja Francesa, el Centro de Orientación Social de Extranjeros, la Oficina Central de Refugiados Españoles (OCRE), el Internacional Refugee Organization, el Internacional Solidarity Comitee norteamericano, el Comité Obrero Judío, Ayuda Obrera Suiza (Oeuvre Suisse d'Entraide Ouvriere, la OSEO en sus siglas en francés), el Centre de Coopération Culturelle et Sociales o Ayuda Sueca (Svenk Hjalpkommitten för Spanien). Pero, por sus importantes ayudas, mencionan de modo especial el Norske Spania Komiteen creado en Noruega por los socialistas Krut Werner, Thora Johanssen, P. Andresen y Kaare Werner, muy solidarios con sus homólogos españoles ${ }^{15}$.

De opinión similar es Manuel Simón, quien piensa que, además de la actuación de una institución como la Cruz Roja, de las aportaciones del Ministerio de Emigración y las del Gobierno de la República en el exilio, de las ayudas de México y de las organizaciones de solidaridad americanas, canadienses, de los cuáqueros, etc., los que más colaboraron con SDE fueron los organismos de los países escandinavos. El más destacado, también para Simón, fue el Norske Spania Komiteen, organismo que había formado un Comité de Ayuda a los republicanos durante la guerra de España y luego, al terminar el conflicto, lo extendió a los exiliados. Como los nórdicos siempre se adelantaban a su tiempo, también dieron facilidades y contribuyeron económicamente para que los niños y jóvenes españoles, hijos de exiliados, viajaran con regularidad como invitados a sus países ${ }^{16}$.

La mayoría de estas organizaciones las citaremos a lo largo del texto, sin embargo, SDE obtuvo el apoyo de muchas otras entidades de solidaridad en general o de ayuda a los refugiados o a los emigrantes y extranjeros más en particular ${ }^{17}$. Todos los contactos necesitaban el visto bueno del partido, el sindicato y las Juventudes Socialistas.

15 MARTÍNEZ COBO y MARTÍNEZ COBO, 1989: 281.

16 Entrevista a Manuel Simón Velasco realizada por Juan Carlos Collado Jiménez, Alcalá de Henares, 11 de abril de 2016, AFFLC, pendiente de catalogación.

17 Por citar algún organismo francés de este último tipo, el Comité Central de SDE mantuvo durante este tiempo una constante relación tanto con el Centre d'Orientation Sociale des Étrangers (COSE), con sede en París, como con el Service Social D'Aide aux Émigrants (SSAE) y el Service Social de la Main-d'Ouvre Étrangère (SSMOE), ambos con servicios centrales en París pero también con delegaciones en Toulouse. Auspiciado por el Ministro de Trabajo y de Seguridad Social como proyección del SSAE, el SSMOE contó con numerosas oficinas departamentales. 
En todo caso, aunque a finales de los años cuarenta la labor quedaba circunscrita basicamente a Francia y a África del norte, porque la falta de medios económicos impedía extender su ámbito de actuación a América, Solidaridad también hacía extensiva la asistencia a los afiliados y a sus familiares residentes en España. Y SDE tuvo su sede en Francia hasta que en el verano de 1976, como ya habían hecho el PSOE y la UGT, la organización fijaba su domicilio en Madrid.

\section{LA AYUDA HUMANITARIA DIRIGIDA A LOS REFUGIADOS ESPAÑOLES EN FrANCIA A MEDIADOS DE LOS AÑOS CUARENTA DEL SIGLO XX}

En 1945 quedaba regulado el marco normativo por el que habrían de regirse los exiliados españoles. De acuerdo con Alicia Alted, ese año Francia generalizó para los españoles la protección de la que ya disfrutaban los desplazados rusos y armenios. Por decreto de 15 de marzo ampliaba a los refugiados que no gozaban de la protección del gobierno de España los beneficios del Convenio Intergubernamental en lo referente al estatuto jurídico internacional de los refugiados de 28 de octubre de 1933. Como no habían sido desposeídos de la nacionalidad española no podían recibir el pasaporte Nansen (documento de identidad especial destinado para quienes no poseían otros documentos), pensado para los apátridas, por lo que los españoles solo tenían derecho a recibir un certificado de identidad y viaje, certificado que expediría una Oficina Central para los Refugiados Españoles en Paris, que, con algunas restricciones, les posibilitaba el acceso al mercado laboral ${ }^{18}$.

En efecto, el 3 de julio de 1945 se constituía la OCRE, y la Delegación en París del Comité Intergubernamental para los Refugiados (CIR) pasaba a encargarse de la atención jurídica y administrativa de los refugiados españoles en la Francia metropolitana. Pero hasta que empezó a funcionar de manera efectiva la citada Oficina, y la Delegación francesa del CIR, fue el Gobierno francés, de manera provisional, el responsable de su protección ${ }^{19}$.

Los españoles eran asimilados a los refugiados Nansen, con derecho a la residencia libre en Francia, y el CIR, formado en 1938, que había extendido su radio de acción a todas las personas obligadas a abandonar su país por peligrar su vida o su libertad, se convertía en 1945 en el organismo encargado de su protección. En adelante, la cobertura administrativa de la OCRE, de la que era responsable el CIR, facilitó mucho la normalización de la situación de los españoles para que pudieran trabajar.

\footnotetext{
18 ALTED, 2003: 74.

19 CERVERA GIL, 11 (Madrid, 1998): 205-206.
} 
El director del Comité Intergubernamental para los Refugiados se alineaba en el mismo año de 1945 con las tesis francesas del gobierno de De Gaulle en el sentido de que el problema de los refugiados españoles no era francés, afectaba principalmente a Francia por la cercanía geográfica, sino que atañía a todas las naciones aliadas. En consecuencia, tenían que llegar contribuciones económicas para estos de las denominadas por Javier Cervera «sociedades benévolas», de las organizaciones internacionales de ayuda a los refugiados. Y empezaron a llegar ayudas para los exiliados españoles de las organizaciones británicas y norteamericanas, fundamentalmente las últimas fueron las que más colaboraron con el $\mathrm{CIR}^{20}$, ayudas muy necesarias para un colectivo castigado.

Además de estas ayudas, que iremos desgranando a lo largo de texto, y otras que ya existían desde la Guerra Civil española, los refugiados también contaron para atender sus necesidades con las organizaciones o instituciones humanitarias independientes o de clara orientación ideológica que se fueron creando y actuaron en el ámbito de Toulouse y el Mediodía francés a mediados de los años cuarenta ${ }^{21}$.

No resulta sencillo cuantificar el número de víctimas del franquismo beneficiadas de la ayuda republicana. Como explica Abdón Mateos, no cabe duda que los refugiados españoles instalados en países de América como México, Chile o la República Dominicana fueron unos privilegiados en comparación con el resto, pero cuando la coyuntura lo permitió, con el desenlace la contienda mundial, los exiliados empezaron también a crear comités de solidaridad ${ }^{22}$.

A principios de 1945 entraba en escena en Francia Solidaridad Democrática Española. Antes de finalizar el año, el Comité Central de SDE había recaudado 450.000 francos de las cuotas de los afiliados y los comités departamentales $300.000^{23}$. El monto total de 750.000 francos franceses destinados a los refugiados y huidos de España, aunque modesto, era una cantidad parecida al gasto mensual dedicado a la ayuda humanitaria por el gobierno de la República en el exilio ${ }^{24}$.

Pero no fue el único organismo solidario formado por las organizaciones vinculadas a los partidos políticos o sindicatos españoles para auxiliar a los exiliados en Francia. Aparte de Solidaridad Democrática Española, dependiente del PSOE y UGT, en la segunda mitad de los años cuarenta del siglo XX proporcionaba también ayuda a los refugiados Solidaridad Española, una organización donde la mayor parte de sus miembros pertenecían a la órbita del Partido Comunista de España (PCE); Solidaridad Internacional Antifascista (SIA),

20 CERVERA GIL, 11 (Madrid, 1998): 199.

21 ALTED, 2003: 75.

22 MATEOS, 2009a: 281-282.

23 MARTIINEZ COBO y MARTÍNEZ COBO, 1989: 280.

24 MATEOS, 2009a: 281. 
emparentada con Solidaridad Obrera de la Confederación Nacional del Trabajo (CNT), o Solidaridad Confederal, ligada igualmente a la CNT pero a su tendencia España Libre ${ }^{25}$. Todos estos organismos asistían a sus militantes.

Tampoco tuvo SDE la exclusiva dentro de las organizaciones socialistas para la prestación de solidaridad a sus afiliados. Salvo en el caso del País Vasco, con el Comité Central Socialista y la Unión General de Trabajadores de Euskadi ${ }^{26}$, no estaba permitida la descentralización según la región de origen, sin embargo, sí podían organizarse comisiones socialistas de estudio y, entre estas, una de las más destacadas fue la asturiana, probablemente la más importante de las comisiones. En 1942, antes de la celebración de los primeros congresos en el exilio, los socialistas asturianos refugiados en Francia, originarios mayoritariamente de las cuencas mineras y diseminados principalmente entre el Macizo Central y los Pirineos, creaban la Comisión Socialista Asturiana. Incluso celebrados los congresos, los asturianos tomaban la decisión de seguir con la labor benéfica que venían realizando desde la Comisión para ayudar a todos los militantes que adolecían de capacidad para ganarse la vida ${ }^{27}$.

En otro ámbito, en 1945 se formaba bajo la presidencia del general Herrera el Comité de Protección a los Refugiados Españoles. A petición de los socialistas exiliados en México el Gobierno del país americano entregaba a esté Comité 50.000 dólares procedentes de los fondos destinados a la Junta de Auxilio a los Republicanos Españoles (JARE), dinero que mantenía bajo custodia, para utilizarlos con los refugiados ${ }^{28}$. Gracias a SDE, estas ayudas, las de Comité de Protección, alcanzaron a la militancia socialista y ugetista ${ }^{29}$.

25 ALTED, 2003: 75.

26 MATEOS, 1993: 6.

27 PÉREZ FERNÁNDEZ, 1990: 7-10.

28 MARTÍNEZ COBO y MARTÍNEZ COBO, 1989: 279. Finalizada la Guerra Civil se creaban dos organismos de apoyo a los exiliados españoles en Francia para colaborar con los costes de los viajes de traslado a los países americanos, principalmente a México y en menor medida a Chile y República Dominicana. Estamos hablando del Servicio de Evacuación de Refugiados Españoles (SERE) y de la citada JARE. El SERE se constituía en París a finales de marzo de 1939 (conformado por un Consejo Ejecutivo en el que figuraban todos los partidos y sindicatos y una Comisión o Ponencia ministerial compuesta por ex ministros del último gobierno de la República afines a Juan Negrín); y el otro ente constituido por miembros del gobierno republicano para ayudar a los exiliados fue la JARE, establecida oficialmente unos meses después, el 31 de julio de 1939 (integrada por un presidente y 8 vocales nombrados por la Diputación Permanente de las Cortes que representaban al PSOE, la corriente prietista, Unión Republicana, Izquierda Republicana, Esquerra Republicana de Catalunya y a los sindicatos UGT y CNT). Véanse en este sentido los capítulos 2 y 3 del libro ya citado de Abdón, MATEOS, 2009a, dedicados respectivamente a la actuación del SERE y de la JARE; o los apartados 1 y 2 de la tesis doctoral de VELÁZQUEZ, 2012, centrada en los organismos de ayuda a los republicanos españoles en México.

${ }_{29}$ Fichero alfabético de damnificados y auxiliados por SDE, María Álvarez García, AFFLC, 866-001 y 867-001. María, afiliada en España y en el exilio a UGT, era una de las mili- 
También estaban los españoles que habían sobrevivido a la deportación en Alemania, compatriotas que a su regreso a Francia creaban la Federación de Deportados $^{30}$. Terminada la ocupación nazi llegaban a Francia procedentes de los campos de prisioneros o de exterminio, y Toulouse fue el destino de la mayoría. Para atender sus necesidades, el 7 de julio de 1945 se estableció la Comisión Regional Administrativa de ayuda a los prisioneros y deportados españoles, en la que confluían miembros de organismos solidarios españoles, de Francia y de otros países agrupados todos en el Comité de organismos de ayuda a los republicanos españoles pro prisioneros y deportados ${ }^{31}$. Solidaridad Democrática Española se ocupó de que revertieran ayudas de este tipo a «sus deportados»»3.

Desde la liberación de Francia los refugiados españoles también recibían ayuda de la Liga de Mutilados e Inválidos de la Guerra de España. Aunque su germen había empezado a manifestarse en 1937, la Liga se constituía oficialmente en un Congreso celebrado en Valencia en el verano de 1938. Con la derrota republicana en la Guerra Civil numerosos mutilados y viudas de guerra se exiliaron a Francia y la Comisión Ejecutiva de la Liga se instaló en París, donde prosiguió con sus actividades. Así hasta 1940. De nuevo por la ocupación alemana, la Liga, al igual que otras organizaciones similares, era ilegalizada y no pudo proseguir con su función hasta la liberación de Francia. Sería también Toulouse el lugar en el que la Liga celebraba el Congreso reconstitutivo a principio de $1947^{33}$.

Si proseguimos con organismos españoles, tampoco queremos pasar por alto el auxilio proporcionado por instituciones de carácter humanitario independientes que actuaban también en el entorno de Toulouse. Durante la Guerra Civil funcionaban dos organismos de la Cruz Roja en España, uno en cada zona, sin embargo, con la derrota final del ejército de la República la Cruz Roja de esta zona pasaba al exilio.

tantes que se beneficiaba de estas ayudas. Nacida el 27 de noviembre de 1901 en Santillana de la Reguera (Oviedo), viuda de guerra, con domicilio en La Guisarre, Savignac de Dura (Departamento de Lot et Garonne), recibía 1.000 francos el 13-III-1946 procedentes del Comité de Protección del Refugiado. María había obtenido el correspondiente aval de SDE de Lot et Garonne.

30 MARTÍNEZ COBO y MARTÍNEZ COBO, 1989: 279.

31 ALTED, 2003: 76-77.

32 Fichero alfabético de damnificados y auxiliados por SDE, Benjamín Alonso Rodríguez, AFFLC, 866-001 y 867-001. Entre los deportados se encontraba Benjamín, nacido el 28 de agosto de 1912 en Oviedo. Era un antiguo empleado de comercio, casado, con domicilio en 80, Rue du Chateau (París), afiliado a UGT y al PSOE en España, y a UGT, JJSS y luego al PSOE también en el exilio. Convaleciente, avalado por Comité Departamental de París, percibía auxilios económicos del IRRC en febrero-abril de 1946 por 1.500 francos y otros 1.500 en mayo-julio. Estuvo deportado en el campo de Mathausen (Austria) desde el año 1942 hasta la liberación del mismo por el ejército de los Estados Unidos.

33 ALTED, 2003: 77-78. 
En el exterior, con el apoyo de la Cruz Roja francesa, y bajo la presidencia del doctor Martí Feded, en abril de 1945 se constituía el Comité de la Cruz Roja Republicana Española (CRRE) en Francia. Una vez más, uno de los principales problemas para su formación estuvo ocasionado por las malas relaciones entre socialistas y comunistas. De todas formas, la CRRE obtenía el reconocimiento oficioso de Francia en febrero de 1946, y la autorización correspondiente para actuar y ayudar a los refugiados españoles, y el gobierno de la República en el exilo también reconocía el organismo e inclusive lo hacía depender en 1947 del Ministerio de Emigración ${ }^{34}$.

En junio de 1945, dos meses después de su formación, la Cruz Roja Republicana Española había montado cerca de la estación de ferrocarril de Toulouse un centro de acogida permanente para ayudar a los españoles (la CRRE formaba parte del Comité de organismos de ayuda a los republicanos españoles pro prisioneros y deportados), y facilitaba el traslado de estos a centros de acogida y hospitales. En un local cedido por la Cruz Roja francesa en Toulouse también funcionó regularmente desde 1946 un servicio médico farmacéutico y se prestaba asistencia social a los refugiados. Con todo, la institución humanitaria también ayudaba a los españoles que pasaban de forma clandestina a Francia a obtener los documentos oficiales en este país ${ }^{35}$.

Estos eran los principales organismos españoles, internacionales con participación española o franceses en colaboración con entidades españolas, que se ocuparon de alguna manera de los exiliados en Francia a mediados de los años cuarenta, mas no podemos olvidar el papel del gobierno de la República en el exilio, al menos hasta principios de los años cincuenta. El Ministerio de Emigración, con Trifón Gómez al frente de la cartera, destinaba un millón de francos para los mutilados entre 1945 y $1947^{36}$. Trifón Gómez era en este tiempo, y lo fue hasta su muerte en 1955, presidente de UGT.

\section{LA EXTENSIÓN Y CONSOLIDACIÓN DE LA ORGANIZACIÓN (1945-1950)}

Entre la colonia española en Francia el peso de los refugiados de la Guerra Civil era muy importante en 1945, pero el éxodo provocado por el conflicto no fue solamente el resultado de los movimientos de población ocurridos entre 1936 y 1939 sino también, aunque no tan masivamente, consecuencia del flujo que se producía una vez terminada la Segunda Guerra Mundial y el incremento de la llegada de clandestinos desde España. Eran personas fugadas

\footnotetext{
34 ALTED, 2003: 78-79.

35 ALTED, 2003: 79-82.

36 MARTÍNEZ COBO y MARTÍNEZ COBO, 1989: 280.
} 
(ex combatientes republicanos represaliados), opositores al régimen de Franco y familiares o allegados de otros refugiados ya instalados en Francia ${ }^{37}$.

Como refiere Abdón Mateos, si hasta 1945 el número de huidos por la represión de la posguerra fue muy bajo, no olvidemos el colaboracionismo del régimen de Petain, con la nueva realidad creada en Europa, liberada totalmente Francia y el resto del continente de la ocupación alemana, la cifra de refugiados políticos españoles llegados al país vecino crecía entre 1945 y 1947. El propio Mateos distingue varias etapas para analizar el paso clandestino de personas a Francia. La primera, y la más importante, al menos por lo que afecta al entorno socialista, se extendió entre los años 1945 y $1950^{38}$.

Los refugiados españoles que llegaban a Francia en 1945 lo hacían preferentemente a través de la frontera vasca y catalana. Unos se fugaban por las montañas pero otros lo hacían escondidos en bodegas de barcos o camuflados como fogoneros en los vagones de las máquinas de carbón de los trenes. Los dirigentes del PSOE y la UGT en el exilio disponían de contactos, de enlaces que se encargaron en muchos casos del paso clandestino de perseguidos y llegaron a contratar a ferroviarios con la finalidad exclusiva de pasar de forma ilegal a Francia a los huidos vinculados a sus organizaciones.

Con el cierre de fronteras con España, producido el 1 de marzo de 1946, no solo no disminuyó este nuevo exilio de posguerra sino que se intensificaba notablemente el paso de clandestinos a Francia en el verano. Solamente en el área de Perpiñán se contabilizaron en un mes hasta 130 pasados. Los centros de acogida preparados eran enseguida insuficientes con el aumento del número de refugiados. El problema tomaba tal dimensión en 1947, año en el que el movimiento de clandestinos españoles fue más significativo, que el delegado del CIR en Francia se vio obligado a pedir apoyo al gobierno de la Republica española en el exilio para la Organización Internacional de Refugiados $(\mathrm{OIR})^{39}$, el organismo de la Organización de las Naciones Unidas (ONU) que asumía la actividad de la extinta Sociedad de Naciones.

Los datos sobre el número total de españoles refugiados en Francia son algo confusos en estos años. De acuerdo con un informe elaborado ya en 1949 por la OIR, había unos 94.000 españoles en Francia en 1945 que se podían considerar como refugiados. Otro informe, en este caso de la Internacional Rescue and Relief Commitee (IRRC), concluía que en mayo de 1947 la cifra estaba en una horquilla entre los 150.000 y los 180.000 . Y hasta los 184.000 refugiados de nacionalidad española se aceptaban en una Comisión Preparatoria de la OIR celebrada en Ginebra el 29 de octubre de $1947^{40}$.

\footnotetext{
37 DREYFUS-ARMAND, 2003: 45-46.

38 MATEOS, 2002: 84-85.

39 CERVERA GIL, 11 (Madrid, 1998): 202 y 207.

40 CERVERA GIL, 11 (Madrid, 1998): 196.
} 
Entre los refugiados españoles procedentes del exilio de la Guerra Civil, y los clandestinos huidos tras la liberación de Francia, el censo elaborado por el Comité Central de SDE a través de las fichas de damnificados tenía registradas a mediados de 1947 a más de 3.000 personas necesitadas y cercanas a sus organizaciones. No obstante, un porcentaje de estos beneficiarios era muy variable. Se trataba de los que al menos teóricamente habían curado sus dolencias y se incorporaban al trabajo. En cualquier caso, solamente entre agosto de 1946 y junio de 1947 el Comité había realizado un desembolso en auxilios individuales de hasta 300.000 francos y una cantidad similar habían empleado en ayudas los comités departamentales ${ }^{41}$.

En concreto, el número de damnificados activos a través de la asociación en diciembre de 1947 ascendía a 679 personas (330 enfermos crónicos sin trabajo, 143 mutilados sin trabajo, 2 niños huérfanos, 26 viudas con familia y sin trabajo, 81 ancianos, 67 hospitalizados sin recursos, 19 familias numerosas y 11 compañeros con hijos o esposa enferma $)^{42}$.

Diciembre de 1947 era el mes elegido para proceder a la renovación del Comité Central de Solidaridad. Manuel Muiño y Miguel Calzada San Miguel continuaban como secretario y tesorero respectivamente, pero Paulino Gómez Beltrán sustituía a Arsenio Jimeno en la presidencia. Junto a algunos jóvenes aparecían ahora dirigentes consagrados de las organizaciones socialistas. Wenceslao Carrillo, Manuel Palacios, José Barreiro y Salvador Martínez Dasi eran los vocales elegidos para este nuevo Comité (en el Comité Central de Solidaridad siempre estaba presente el máximo representante de las Juventudes Socialistas y en esas fechas Dasi era el secretario general) ${ }^{43}$. No solo se elegían los cargos del Comité Central de SDE con sede en Toulouse, año tras año los comités departamentales también procedían a la renovación de todos o alguno de sus miembros electos ${ }^{44}$.

41 Memoria de gestión del Comité Central, Toulouse, 30-VI-1947, AFFLC, 864-004: 3-4.

42 Memoria de gestión del Comité Central, Toulouse, 31-XII-1947, AFFLC, 864-004: 2. Los hospitalizados sin recursos eran en uno de los colectivos sometidos a un seguimiento preferente por parte de SDE. Esto se traducía, además de visitas periódicas a sanatorios y hospitales llevadas a cabo por la propia militancia, en ayudas económicas. Ángel Aguera Martínez, nacido en 1906 en Murcia, casado, domiciliado en Francia en 2, Quai Turgot, Tronjet, Departamento de Allier, era un minero de profesión afiliado a UGT y al PSOE en el exilio avalado por el Comité Departamental de Allier. Enfermo, hospitalizado por ello en septiembre de 1946 y marzo de 1947, fue auxiliado económicamente por el Comité Central de SDE con 1.000 francos el 23-IV-1947, y con otros 1.000 el 19-XI-1947. Consúltese: Fichero alfabético de damnificados y auxiliados por SDE, Ángel Aguera Martínez, AFFLC, 866-001 y 867-001.

43 Certificado del prefecto de Haute-Garonne declarando los cambios en la composición de los miembros del Comité Central, Toulouse, 18-XII-1947, AFFLC, 864-010.

44 El Comité Departamental de SDE de Landes lo hacía, por ejemplo, a principios de 1947. Boletín de la Unión General de Trabajadores de España en el exilio: adherida a la Federación Sindical Internacional, 29, marzo 1947: 4. 
Resulta interesante en este punto examinar cómo era la actividad en Francia de un Comité Departamental de Solidaridad Democrática Española elegido al azar. Coordinado con las delegaciones locales, el Comité de Loiret, con capital en Orleans, no solo repartía 47.450 francos entre los damnificados dentro del Departamento durante 1947 sino que había conseguido enviar otros 11.754 en el mismo periodo al Comité Central. También había celebrado Loiret una velada familiar el 24 de diciembre con un sorteo destinado a incrementar el fondo de ayuda, rifa que reportaba un beneficio de 7.383 francos a la organización ${ }^{45}$.

Desde el comienzo de su funcionamiento y hasta mediados de 1947, gracias a la red de contactos e intermediaciones, el Comité Central de Solidaridad había obtenido de los organismos internacionales importantes ayudas en especie aunque también aportaciones económicas. Nos referimos a medicamentos y artículos de cura, ropa y gafas procedentes del International Solidarity Committee o a las contribuciones en dinero del International Rescue and Relief Committee. Antes de cesar en su actividad el CIR había atendido peticiones superiores a los 250.000 francos al mes. Gracias a instituciones humanitarias como Ayuda Obrera Suiza se habían financiado estancias de hijos de socialistas y ugetistas en el país helvético. También había llegado apoyo económico, víveres y ropas del Comité de Solidaridad de México, integrado por UGT, PSOE y las JJSS en ese país, y otras basadas en ropa y medicamentos a través del Ministerio de Emigración republicano. Todo esto sin desdeñar los donativos individuales de afiliados, amigos y simpatizantes realizados desde los Estados Unidos de América, por citar otras ayudas ${ }^{46}$.

Con unos medios propios insuficientes, todavía en 1947, el Comité Central de Solidaridad gestionaba nuevas ayudas internacionales, tanto oficiales como particulares, pero ahora se centraba especialmente en la OIR, organización con sede en Ginebra y delegación en París. En total, recibieron el auxilio de la Organización Internacional para los Refugiados 140 militantes en agosto y septiembre, 50 en octubre y 100 en noviembre y diciembre de 194747 . Creada el 20 de agosto de 1946 para ocuparse de los refugiados ocasionados por la Segunda Guerra Mundial, la OIR no tomaba el relevo del CIR de forma efectiva hasta el 1 de julio de 1947. No lo tendría fácil el organismo de la ONU si tenemos en cuenta el incremento de la llegada clandestina de españoles a Francia a través de los Pirineos.

Las medidas represivas del régimen de Franco incrementaban la cifra de huidos, y se estima que llegaban a Francia de forma ilegal otros 11.000 espa-

45 Boletín de la Unión General de Trabajadores de España en el exilio: adherida a la Federación Sindical Internacional, 42, abril 1948: 5.

46 Memoria de gestión del Comité Central, Toulouse, 30-VI-1947, AFFLC, 864-004: 4-7.

47 Memoria de gestión del Comité Central, Toulouse, 31-XII-1947, AFFLC, 864-004: 4-10. 
ñoles en $1948^{48}$. No era sencillo entre todos ellos calcular los evadidos vinculados a las organizaciones socialistas, pero SDE se hacía eco del movimiento de clandestinos que huían de la dictadura franquista. El Comité Central había gastado 325.000 francos hasta diciembre de $1948^{49}$.

Los españoles que pasaban a Francia, generalmente obreros industriales, jornaleros agrícolas y pequeños propietarios ${ }^{50}$, lo hacían muchas veces de forma individual. Uno de los que sorteaba de forma clandestina la frontera francesa en 1948 era Eugenio Valera López. En Francia se reagrupaba con su padre, refugiado político, y se afiliaba a las organizaciones socialistas en el exilio. En España trabajaba como albañi ${ }^{51}$. Sin embargo, por lo que se refiere al colectivo socialista y ugetista, lo más destacado en 1948, gracias a un viaje organizado por Indalecio Prieto desde el exilio de Veracruz, México, fue el paso clandestino a Francia de los últimos guerrilleros asturianos que ofrecían resistencia al franquismo en las montañas del norte. Concentrados en el puerto de Gijón, más de una veintena de maquis, muy bien vestidos y arreglados para no levantar suspicacias a la policía, conseguían subir el 23 de octubre de 1948 a una barca de pescadores con destino a la localidad vasco-francesa de San Juan de Luz. Entre los asturianos se encontraban militantes históricos como José Mata Castro o José Lafuente Fernández ${ }^{52}$.

Solidaridad no organizaba el paso de huidos desde España, no obstante, una vez que entraban en Francia era SDE quien prestaba ayuda o les facilitaba la obtención de los papeles reglamentarios ${ }^{53}$. Solidaridad Democrática Española, por delegación de las ejecutivas, avalaba a los clandestinos para que se acogieran al estatuto de refugiado con los organismos de las Naciones Unidas. Y un dato importante, la mayor parte de los refugiados avalados por Solidaridad no eran militantes activos al pasar la frontera sino antiguos afiliados ex presos o perseguidos una vez acabada la guerra.

Ahora bien, si al principio Francia había favorecido una actitud permisiva por parte de los comisarios regionales del sur a la hora de acoger a los que huían de España, porque entendían que lo hacían por motivos políticos, la política emigratoria francesa cambió definitivamente en 1949. En realidad, la

48 MARTÍNEZ COBO y MARTÍNEZ COBO, 1989: 280.

49 Memoria de gestión del Comité Central, Toulouse, 31-XII-1948, AFFLC, 864-004: 13-14.

50 MATEOS, 2002: 89.

51 Entrevista a Eugenio Valera López realizada por Bruno Vargas, Cugnaux (Francia), 8 de junio de 2007, AFFLC, 3645-002.

52 GARCÍA, 2005: 99-100.

53 Fichero alfabético de damnificados y auxiliados por SDE, Marcelino Alfaro Ferrando, AFFLC, 866-001 y 867-001. Marcelino, nacido el 14 de agosto de 1925 en Siétamo (Huesca), soltero, albañil de profesión, que trabajaba como cultivador en Vieille Adour (Haute Pyrénées), recibía como pasado de España un auxilio económico del Comité Central de SDE de 500 francos el 3-IV-1946. 
legislación elaborada por el Ministerio del Interior durante 1948 limitó ya en gran manera la llegada masiva de emigrantes.

En efecto, aunque su instalación en el interior del país no fructificó, una disposición de 26 de marzo de 1948 ordenaba el alejamiento de los departamentos del suroeste de Francia de los refugiados españoles considerados indeseables, catalogados como peligrosos por sus antecedentes, así como de los clandestinos procedentes de España ${ }^{54}$. Era una circular restrictiva que afectaba a la acogida de españoles en algunos departamentos franceses saturados de extranjeros.

De igual modo, como empezaba a crecer también el número de parados, la medida se completaba con otra emanada del Ministerio de Trabajo francés, de 2 de noviembre de 1948, que rechazaba a los inmigrados que no aceptasen ocupación en las minas y en la agricultura, sectores donde era necesaria la mano de obra extranjera ${ }^{55}$. En su mayoría trabajadores sin cualificar o agricultores, los españoles tuvieron que dedicarse a la construcción o a los trabajos relacionados con la mina o la industria.

Para ayudar a sus afiliados se habían constituido también comités de SDE en países europeos como Bélgica, que daba apoyo a los militantes necesitados de ese país; sin embargo, no había comités funcionando en Gran Bretaña, de lo que se encargaba por defecto la Unión General de Trabajadores. Y respecto a la ayuda llegada de fuera de Europa, se recibían en Francia envíos periódicos del Comité de México pero tampoco había Comité de Solidaridad organizado en Venezuela ni en Chile, por lo que era igualmente el sindicato quien se encargaba de remitir con regularidad las cuotas de solidaridad ${ }^{56}$.

También habían afectado negativamente los cambios en los gobiernos del exilio. Desde que no estaba como ministro de Emigración de la República en el exilio el socialista y ugetista Trifón Gómez habían cesado las ayudas económicas procedentes del Ministerio. Por el contrario, fue muy destacada durante 1948 la actuación que los socialistas escandinavos, suecos, daneses y noruegos, realizaban a favor de los exiliados republicanos. Ayuda Sueca, en concreto, desarrollaba una importante labor benéfica con donaciones de víveres, ropa y calzado. Sin despreciar la ayuda económica que prestaba para aparatos ortopédicos, operaciones, adquisición de gafas y similares el Fondo Humanitario formado por la OCRE, también había obtenido SDE en 1948 muchos beneficios para sus afiliados a través del International Rescue and Relief Committee y de los donativos en dinero de la Sección Local núm. 16 de Obreros de Cafés y Restaurantes de Nueva York, perteneciente a la Fede-

54 DREYFUS-ARMAND, 2003: 47.

55 DREYFUS-ARMAND, 2003: 47.

56 Memoria de gestión del Comité Central, Toulouse, 31-XII-1948, AFFLC, 864-004: $15-16$. 
ración Americana del Trabajo. Los ingresos de niños y adolescentes necesitados en colonias infantiles, en este caso por la generosidad de la OSEO, empezaban a ser también cada vez más habituales. Y es que el número de damnificados no paraba de crecer en estos primeros años. De acuerdo con los datos ofrecidos por el Comité Central, el censo de SDE superaba a finales de 1948 las 5.000 fichas entre damnificados temporales y circunstanciales ${ }^{57}$.

Paradójicamente, y pese a la intensa actividad desarrollada por la asociación, no será hasta principios de 1949 cuando aparezcan las primeras referencias específicas a SDE en la Memoria de un congreso celebrado por UGT, el III Congreso en el exilio. La creación de Solidaridad había posibilitado la solución de graves problemas humanos pero las dificultades económicas impedían atender muchas necesidades de $\operatorname{los}$ afiliados $^{58}$. Esta era una de las principales conclusiones del documento.

Desde 1949 solamente se permitía ya la entrada en Francia de un reducido número de personas y siempre previa demostración de que se trataba de perseguidos del régimen franquista. Tampoco resultó fácil a SDE avalar a los militantes o familiares que llegaron a Francia durante el transcurso de este año, todo lo contrario.

Aunque el Comité Central de Solidaridad avalaba directamente a 450 personas no hacía lo mismo con los individuos que sorteaban la frontera por delitos comunes ni con los que pasaban a Francia realmente por motivos econó$\operatorname{micos}^{59}$. Aun cuando hubo clandestinos que intentaron encontrar un trabajo que les permitiera vivir de una manera más decente en el país vecino, la gran mayoría cruzaban la divisoria para escapar del acoso al que estaban sometidos en España. También había entre los avalados por SDE familiares de refugiados políticos españoles ya regularizados en Francia, esposas, hijos y hermanos que buscaban reencontrarse con sus familiares. Procedente de la localidad toledana de La Nava de Ricomalillo, ahí está el caso de Vicente García. Pasaba de manera clandestina a Francia en 1949 para reunirse con su padre, exiliado en Toulouse, al que no veía desde los años de la Guerra Civil ${ }^{60}$.

Como otros hijos de exiliados socialistas y ugetistas Vicente García también obtenía el estatuto de refugiado político, pero la consideración que debían tener los clandestinos españoles comenzó a generar muchas dudas y con-

57 Memoria de gestión del Comité Central, Toulouse, 31-XII-1948, AFFLC, 864-004: 23 y $5-11$.

58 Memoria que presenta al Tercer Congreso la Unión General de Trabajadores de España en el Exilio. La Comisión Ejecutiva, Toulouse, 20 al 23 de enero de 1949, AFFLC, C/03/20: 9. Las memorias de los congresos siguientes de UGT contarán ya, a partir de ese año, con un apartado específico dedicado a Solidaridad.

59 Memoria de gestión del Comité Central, Toulouse, 31-XII-1949, AFFLC, 864-004: 10.

60 Entrevista a Vicente García García realizada por Juan Carlos Collado Jiménez, Talavera de la Reina, 6 de marzo de 2009, AFFLC, 4203-002. 
trariedades a las autoridades galas. Los prefectos de los departamentos fronterizos con España encontraban cada vez más complicado reconocer a los emigrantes económicos de los refugiados.

Con la intervención de Solidaridad se habían organizado colonias infantiles y gestionado hospitalizaciones, se habían distribuido auxilios a embarazadas o becas a estudiantes. Con todo, SDE tenía en 1949 a más de 3.000 enfermos, ancianos e inválidos necesitados de ayuda y a unos 2.000 niños, hijos de afiliados, que precisaban alimentos ${ }^{61}$.

Para atender tantas necesidades económicas y materiales, la Organización Internacional de Refugiados, el International Solidarity Committee (ISC) de Nueva York, el International Rescue and Relief Committee, la Sección Local $\mathrm{n}^{\mathrm{o}} 16$ de Obreros de Cafés y Restaurantes de Nueva York, el Comité Obrero Judío, Inst. Ladies Garment Workers Union de Nueva York, Bund Union des Socialistes Juifs, Ayuda Obrera Suiza, Don Suisse, Cruz Roja Suiza, Ayuda Sueca, Norske Spania Komiteen y el Comité de Toulouse de la Cruz Roja Francesa habían sido los principales apoyos ${ }^{62}$. Con un censo compuesto a finales de 1949 por 5.500 fichas y 650 damnificados en activo, de los que 400 recibían auxilio mensual, el esfuerzo desarrollado por SDE en labores de ayuda o gestión había sido considerable ${ }^{63}$.

Como novedad, en 1949 pasaba a formar parte del Comité Central de Solidaridad otro destacado militante socialista, Carlos Martínez Parera, que en 1948 había entrado también en la Ejecutiva del PSOE ${ }^{64}$. Ya venía aportando su experiencia en tareas de coordinación de las ayudas internacionales recibidas por SDE, durante la ocupación nazi de Francia había trabajado en la Cruz Roja Suiza y estuvo vinculado después al Ministerio de Emigración con Trifón Gómez (entre otros puestos de responsabilidad luego también fue el administrador del Fondo Humanitario Español ${ }^{65}$, por lo que la elección de Parera estaba especialmente indicada por razones prácticas.

Entre la colonia de españoles en Francia la cifra de refugiados estaba en torno a los 125.000 en 1950, la mayoría establecidos en el Mediodía francés, en ciudades como Toulouse, Perpiñán, Montauban, Carcassonne, Albi y Pau. En el Departamento de Haute Garonne había 20.248 españoles, 8.000 de ellos refugiados. Y de los 11.500 que vivían en Toulouse, 6.000 eran también refu-

61 Informe sobre la situación de los refugiados politicos elaborado por el Comité Central, Solidaridad Democrática Española, AFFLC, 864-008: 2-3.

62 Informe sobre la situación de los refugiados politicos elaborado por el Comité Central, Solidaridad Democrática Española, AFFLC, 864-008: 3-4.

${ }_{63}$ Memoria de gestión del Comité Central, Toulouse, 31-XII-1949, AFFLC, 864-004: 7.

64 Certificado del prefecto de Haute-Garonne declarando los cambios en la composición de los miembros del Comité Central, Toulouse, 25-II-1949, AFFLC, 864-010.

65 MARTIINEZ COBO y MARTÍNEZ COBO, 1989: 281. 
giados $^{66}$. Agrupados en las zonas donde había arraigado la presencia española, el colectivo de refugiados políticos de nuestro país era el más elevado de Francia en estos años.

\section{DE LA ESPAÑa QUE HUYE A LA ESPAÑa QUE EMIGRA (1951-1956)}

En los años cincuenta continuaron llegando personas a Francia por la persecución a la que se veían sometidas en España o en busca de mejores condiciones de vida, pero las estadísticas bajaron mucho desde los últimos meses de $1950^{67}$. Comenzaba la disolución de la Organización Internacional de Refugiados, hasta ese momento bastante generosa con las concesiones de los estatutos, y desde que las autoridades francesas habían asumido la tarea de realizar las encuestas para otorgar la nueva situación legal de los clandestinos el número de rechazados se había incrementado notoriamente (la OIR dejaba definitivamente de funcionar en 1952, año en el que era reemplazada por el Alto Comisionado de las Naciones Unidas para los Refugiados, fundado en 1950, conocido como ACNUR en sus siglas en castellano) ${ }^{68}$. Solidaridad dedicaba en torno a un millón de francos para la ayuda a los Refugiados entre 1948 y $1951^{69}$, no obstante, si en el año 1949 tramitaba 450 avales este número quedó reducido a 45 en 1951 y a 15 en $1952^{70}$.

Con otra variación importante, desde el 22 de septiembre de 1952, con la efectiva disolución también de la OCRE, era la Oficina Francesa de Protección de Refugiados y Apátridas, Office Français de Protection des Refugies et Apatrides (OFPRA), el organismo que pasaba a hacerse cargo de la protección jurídica de los refugiados españoles en Francia. La OFPRA se creaba para asegurar la aplicación de los convenios y acuerdos internacionales en materia de refugiados, por lo que las peticiones para obtener los certificados de refugiados a los reconocidos como exiliados políticos se tramitaban ahora desde esta Oficina.

Es evidente que entre los motivos del cambio de tendencia iniciado a fines de los años cuarenta ocupaba un lugar destacado la normalización de las relaciones con España, hecho que influyó decisivamente en la caída de la emigración clandestina desde 1951, aunque también, sobre todo ya en los años 1952 y 1953, la restricción en la concesión de estatutos a los refugiados.

\footnotetext{
66 ALTED, 2005: 100.

67 Memoria de gestión del Comité Central, Toulouse, enero de 1951, AFFLC, 864-004: 6-7.

68 DREYFUS-ARMAND, 203: 47.

69 MATEOS, 2002: 90.

70 MARTÍNEZ COBO y MARTÍNEZ COBO, 1989: 280.
} 
Incluso el número de refugiados que regresaban a España superaba al de los que se acogían a ese estatus en Francia. En total, la cifra de refugiados españoles en toda la primera mitad de la década de los cincuenta ascendió a tan solo 260 personas. Eso sí, pasaban la frontera de los Pirineos socialistas y ugetistas como Antonio Trigo Mainal, Antonio Hernández Vizcaíno, Máximo Rodríguez o los dirigentes catalanes Ramón Morera y Ramón Porqueras Fonfría. Muchos de estos refugiados eran también familiares de antiguos exilia$\operatorname{dos}^{71}$. Trigo Mainal se incorporaba al Comité Central de Solidaridad en $1951^{72}$.

Desde ese año las autoridades francesas solamente otorgaban ya el derecho de asilo como refugiado político a los huidos de España en casos excepcionales. No deja de ser significativo que en 1951 prefecturas como la de Pirineos Occidentales reintegraron a España a todos los que habían atravesado la frontera $^{73}$. Y la entrada de clandestinos siguió bajando en 1952. Según DreyfusArmand, se registraron escasamente 10 clandestinos españoles al mes durante 1952, de los cuales únicamente fueron admitidos 10 en todo el año ${ }^{74}$.

El abanico de damnificados por SDE, aunque había disminuido en número, seguía siendo amplio y diverso. Por el cómputo realizado en abril de 1952, sin contar casos eventuales o no permanentes, entre ciegos (10 personas), mutilados (114), ancianos (98), hospitalizados (68), enfermos crónicos (93), «reeducandos» (9) y asilados (12), el Comité Central había tenido que actuar sobre un censo de 404 afiliados necesitados. Pero la organización fundada por el PSOE, UGT y las JJSS no solo había centrado su actuación en el exterior y principalmente en Francia, entre el 1 de enero de 1951 y el 30 de junio de 1952 el Comité Central de Solidaridad remitía socorros a familiares de presos en España por un importe total de 310.000 francos $^{75}$.

En consecuencia, el presupuesto correspondiente a 1952 era aún más alto que el del año anterior. Sin contar los ingresos locales y los de los distintos comités departamentales, el presupuesto de 1951 ascendía a 630.510 francos y a 985.114 el de $1952^{76}$. Entre 1951 y noviembre de 1953 la ayuda realizada de manera individual por el Comité Central de Solidaridad —en dinero o en especie-, había llegado a 248 afiliados ${ }^{77}$.

71 MATEOS, 2002: 95-96.

72 Certificado del prefecto de Haute-Garonne declarando los cambios en la composición de los miembros del Comité Central, Toulouse, 17 de mayo de 1951, AFFLC, 864-010.

73 Informe sobre la situación de los refugiados españoles a su llegada a Francia elaborado en función de una circular confidencial del Ministerio del Interior francés, Toulouse, 11-VIII-1951, AFFLC, 932-001: 1.

74 DREYFUS-ARMAND, 2003: 48.

75 Informe sobre la situación de los refugiados politicos elaborado por el Comité Central, Solidaridad Democrática Española, agosto 1952, AFFLC, 864-008: 1 y 4.

76 MARTÍNEZ COBO y MARTÍNEZ COBO, 1989: 281.

77 Memoria de gestión del Comité Central presentada al V Congreso de UGT, AFFLC, 864-005: 2. 
Algunos de estos damnificados llevaban años percibiendo ayudas. Ahora bien, si están documentados supuestos de socialistas y ugetistas que comenzaban a recibir prestaciones a través de Solidaridad, directas o indirectas, y estas se alargaban en el tiempo hasta prácticamente el momento de su defunción, tampoco faltan ejemplos en los que se retiraba el aval a otrora damnificados porque no dedicaban los recursos a los fines para los que la organización los había prestado ${ }^{78}$.

Otro de los canales de financiación interna de Solidaridad para el desarrollo de su actividad eran los donativos de los militantes. Asimismo, las recaudaciones voluntarias procedentes de colectas, tómbolas, festivales, representaciones de grupos artísticos o comidas a beneficio de la organización cobraron también más importancia para SDE si cabe conforme bajaban los ingresos por las cuotas de los afiliados. Los fondos tenían que enviarse directamente al tesorero, a Miguel Calzada, y todos los meses el Comité Central ingresaba dinero por estos conceptos.

¿De dónde procedían las principales ayudas externas en esta época? Los noruegos del Norske Spania Komiteen, siempre fraternales con los exiliados españoles, realizaban en agosto de 1953 una de las mayores entregas de ropa y calzado a SDE en mucho tiempo, aunque también habían sido cuantiosos los donativos de ropa y alimentos procedentes de organizaciones como Ayuda Obrera Suiza, Entraide Ouvriere Française (EOF) o el Internacional Solidarity Committee. Cesaba la misión del International Rescue Committee, era disuelta la sección española, pero en marzo de 1953 había surgido con fuerza un nuevo comité en Estados Unidos para recaudar fondos con destino a los refugiados españoles en Francia, el Spanish Refugee Aid (SRA). Solidaridad recibía la visita en Toulouse de varios representantes de esta institución y ya les habían enviado datos con nombres de posibles damnificados ${ }^{79}$.

¿Qué sabemos de la nueva organización? Vinculada políticamente a la izquierda intelectual norteamericana, SRA nacía en un momento en el que el

78 Expediente de ayuda a damnificados de José Aguilera Pérez, AFFLC, 879-014. José, casado, con tres hijos a su cargo, natural de Hospitalet de Llobregat (Barcelona) donde había nacido el 24 de mayo de 1919, era apresado en España en abril de 1953. Liberado, entraba en Francia como clandestino en la primavera de ese mismo año. De profesión mecánico, sin trabajo, recibió un auxilio económico de 8.000 francos el 15-V-1953. En diferentes documentos se describe su participación en la Guerra Civil española y también en la Guerra Mundial, enrolado en los batallones de marcha franceses. El damnificado quería encontrar a su mujer francesa y sus dos hijas para asentarse junto a ellas en Francia, para lo que SDE le prestaba los citados 8.000 francos que estaba obligado a devolver cuando consiguiera un empleo. Si bien era avalado inicialmente, en otro documento, fechado el 18-VII-1953, se detalla que le retiraban el aval porque no estaba dedicando los recursos a los fines pactados (buscar a su familia y encontrar trabajo) y le instaban a devolver el dinero prestado bajo amenaza de denuncia.

79 Memoria de las actividades del Comité Central desde el IV Congreso de la UGT abril 1951, AFFLC, C/03/22: 2-4 y 8-9. 
régimen de Franco comenzaba a ser reconocido en el ámbito internacional. Esta izquierda, que había participado en la Guerra Civil española, que colaboraba en revistas y debates, daba un paso más en 1952 cuando la neoyorquina Nancy Macdonald, luego secretaria de la organización, viajaba a Europa y se interesaba en Francia por los refugiados españoles. Vistos los informes emitidos por el International Rescue Committee sobre familias españolas exiliadas, informes facilitados a este organismo por entidades como la Liga de Mutilados e Inválidos de la Guerra de España, Solidaridad Internacional Antifascista, Solidaridad Socialista del POUM o la propia Solidaridad Democrática Española, Macdonald tomaba conciencia de la precariedad en la que vivían los refugiados. En el acta fundacional y en los estatutos del SRA aparecía como objetivo ayudar a paliar los sufrimientos de los refugiados republicanos españoles «anticomunistas», y este carácter acompañó a la organización a lo largo de sus años de actividad ${ }^{80}$.

Sobre las prestaciones percibidas por el colectivo de mutilados en particular, no hay duda de que gracias a la intervención de Solidaridad muchos imposibilitados de la diáspora pudieron acogerse a ciertas ayudas que sin su intermediación no habrían conseguido posiblemente nunca disfrutar. Algunos de los exiliados españoles no solo lucharon en la Guerra Civil, también combatieron en Francia durante la Segunda Guerra Mundial y acabaron por ello discapacitados. Poco a poco se fueron creando en Francia estructuras del Estado del Bienestar, con servicios para cuidar a los antiguos combatientes, y se instauraron pensiones para mutilados e indemnizaciones por el hecho de participar en la guerra o haber estado internado en un campo de concentración. Solidaridad Democrática Española también daba el instrumento de ayuda administrativa para beneficiarse en estos casos.

SDE mantenía muy buenas relaciones con la Liga de Mutilados e Inválidos de la Guerra de España. Lo que pudiera corresponder a los socialistas y ugetistas pertenecientes a la Liga, de las ayudas que la Liga recibía de la Oficina Técnica Española (OTE), les seguía llegando a los afectados. La propia OTE apoyaba con aportaciones directas la obra del Comité Central de Solidaridad $^{81}$.

Aparte de ayudas procedentes de remesas que llegaban al Gobierno de la República en el exilio o el dinero asignado de la Oficina Técnica ${ }^{82}$, la Liga de Mutilados empezó a recibir subvenciones a partir de 1952 de un comité especial creado por Indalecio Prieto. Con la conformidad de Trifón Gómez, presidente del PSOE, Prieto tomaba la decisión de encargar la custodia y adminis-

80 ALTED, 2003: 84-85.

${ }^{81}$ Memoria de las actividades del Comité Central desde el IV Congreso de la UGT abril 1951, AFFLC, C/03/22: 9-11.

82 BOTELLA PASTOR, 2002: 48, 113 y 175. 
tración de los fondos de la JARE bajo su control a una comisión y que los intereses de dichos fondos contribuyeran a financiar, entre otros organismos, a la Liga de Mutilados e Inválidos de la Guerra de España. La comisión, denominada «Comisión Mexicana de Ayuda a los Refugiados», tuvo actividad hasta los años sesenta ${ }^{83}$.

Estaban igualmente las ayudas presentadas al Fondo Humanitario desde 1952. Formado por el Gobierno francés para prestar asistencia a los refugiados políticos españoles residentes en ese país, el Fondo concedía ayudas a militantes o familiares vinculados a las organizaciones socialistas por las gestiones de Solidaridad Democrática Española ${ }^{84}$.

La acción solidaria había tenido además en cuenta todos estos años a los familiares de los socialistas presos en las cárceles españolas. Como dato, en abril de 1954 SDE prestaba ayuda humanitaria a 30 familias de presos ${ }^{85}$.

No se habían otorgado 14 supuestos porque no cumplían las condiciones, pero el número de avales extendidos a personas procedentes de España por el Comité Central, como delegado de las Comisiones Ejecutivas, sumó 70 casos en $1954^{86}$. Las dificultades para los españoles que entraban clandestinamente en Francia no aminoraron ese año, sin embargo, gracias a las solicitudes tramitadas por las organizaciones de refugiados algunos de los recién llegados fueron reconocidos como refugiados políticos y autorizados a permanecer en el país.

El problema venía con los clandestinos que no pasaban por Toulouse. Estos normalmente eran devueltos a España o inscritos en la Legión. Organizaciones como SDE, respaldada por el PSOE y la UGT, presionaban para que se centralizara en Toulouse la tramitación de la clasificación de los españoles que llegaban, sobre todo porque era allí donde estaban los organismos nacionales de las distintas organizaciones de exiliados y así se solventaba que tuvieran que ir de un departamento a otro o posibles errores en la catalogación de refugiados políticos ${ }^{87}$. Evitar situaciones tan susceptibles como la de los

83 La Comisión, integrada por Julián Borderas, Juan Ruiz Olazarán y Eduardo Díaz de Junguitu, destinaba \$1.325.252,80 en donaciones a la Liga de Mutilados e Inválidos de Francia en el periodo que abarca agosto de 1952 y diciembre de 1957. VELÁZQUEZ, 2012: 599-600.

84 Expediente de ayuda a María Alamán Roca, viuda de Verdaguer, AFFLC, 879-022. María era una ama de casa nacida en enero 1888 en Balaguer (Lérida). Domiciliada en 8, Rue Daussargues de Toulouse (Haute Garonne), con dos familiares a su cargo, solicitaba 7.703 francos al Fondo Humanitario Español en documento dirigido al presidente del Comité de Distribución del mismo el 29-IV-1952.

85 MATEOS, 2002: 97.

86 Memoria de gestión del Comité Central, Toulouse, 25-I-1955, AFFLC, 864-005: 6-7.

87 Informe sobre la situación de los refugiados españoles a su llegada a Francia elaborado en función de una circular confidencial del Ministerio del Interior francés, 17-I-1954, AFFLC, 932-001: 1-2. 
jóvenes que eran detenidos al cruzar la frontera e invitados a enrolarse en la Legión Extranjera, para no ser devueltos a nuestro país, se había convertido en una cuestión prioritaria.

En cuatro años había disminuido mucho entre los españoles que llegaban a Francia el número de refugiados políticos y, por tanto, de legalizaciones. No obstante, si entre 1954 y 1956 SDE negaba el aval a 27 individuos procedentes de España porque no entraban dentro de los requisitos para obtener el estatuto de refugiado político, y solamente buscaban ayudas económicas o gestiones a su favor, Solidaridad también había posibilitado avales para renovar el estatuto de refugiado, Certificado de Refugiado de L'Office Français de Protection des Réfugiés et Apatrides, a 70 personas $^{88}$.

El Comité Central de Solidaridad también facilitó en este tiempo la tramitación de las demandas de ingreso de ancianos afines a sus organizaciones en establecimientos para personas mayores en Francia. Y seguía con mucho interés la situación de los que ya estaban acogidos en estos centros, a los que llevaban libros y prensa y prestaban auxilio material o moral. Era considerado modélico la «Maison Beau Séjour», localizado en Hyères, con un edificio muy moderno y perfectamente acondicionado, pero había ancianos socialistas en numerosos asilos franceses ${ }^{89}$. Muy importante la implicación de los militantes dedicados al contacto humano con los «compañeros» enfermos, ingresados en hospitales o internados en residencias.

Las gestiones realizadas por SDE con el delegado en Francia del ACNUR se habían centrado casi exclusivamente en la reposición de ayudas a enfermos y ancianos. Sin embargo, como órgano intermediario, el Comité Central de Solidaridad si había intensificado lazos y diversificado los tipos de ayudas entre 1954 y 1956 con el Spanish Refugee Aid, tanto con su presidente como con su secretaria o las delegadas en Francia. Todo lo que facilitaba el SRA a Solidaridad Democrática Española lo hacía de forma directa para sus afiliados y lo obtenía principalmente a través de donaciones de particulares o como consecuencia de la celebración de actos benéficos ${ }^{90}$.

Solidaridad seleccionaba los casos de mayor gravedad a través de la ficha del damnificado, trasladaba los datos a los organismos y estos, muchas veces, establecían el contacto y el pago de lo que correspondiese directamente con el afectado. Las donaciones en estos supuestos eran finalistas, para cosas muy concretas, y no llegaban de manera directa a la organización socialista sino a sus damnificados.

88 Memoria de gestión del Comité Central presentada al VI Congreso de UGT, AFFLC, 864-005: 15-16.

89 Memoria de gestión del Comité Central presentada al VI Congreso de UGT, AFFLC, 864-005: 8-9.

90 Memoria de gestión del Comité Central presentada al VI Congreso de UGT, AFFLC, 864-005: 5 y 11-12.

Hispania, 2018, vol. LXXVIII, nº . 259, mayo-agosto, págs. 409-437, ISSN: 0018-2141, e-ISSN: 1988-8368 https://doi.org/10.3989/hispania.2018.011 
Los españoles residentes en Francia que reunían las condiciones se empezaron a beneficiar igualmente de los derechos concedidos por la legislación francesa a través de la denominada tarjeta de económicamente débil, «Carte d'Economiquemant Faible», la Ley Cordonnier de 1948 o el Fondo de Solidaridad Nacional. La posesión de la tarjeta daba a los titulares derecho a diversos auxilios, permanentes y circunstanciales, y el Comité Central de Solidaridad recomendaba su solicitud a todos los que poseían el certificado de la OFPRA. También llevaba tiempo informando SDE a sus afiliados de los derechos que concedía a los refugiados españoles la llamada Ley Cordonnier ${ }^{91}$.

Según finalizaba la primera mitad de la década de los años cincuenta la actividad desarrollada por Solidaridad fue, en general, menor, y estuvo dirigida esencialmente hacia los enfermos y los más necesitados en el exilio, sin olvidar a las familias de los presos encarcelados en España. Aparte de la disminución paulatina de la entrada de clandestinos por las dificultades y exigencias impuestas por las autoridades francesas para la autorización de la residencia, con la extensión de algunos beneficios de los derechos de los seguros sociales o de otras ventajas a españoles establecidos en Francia comenzaba a decrecer el número de personas que solicitaban la ayuda de SDE en los casos de vejez o enfermedad.

Tampoco era posible a la altura de 1956 pagar los subsidios a los más necesitados con los recursos propios. El mismo Manuel Muiño, secretario de SDE y secretario general de UGT, reconocía que en estas fechas la mejor labor que podía llevar a cabo la organización eran gestiones dirigidas al aprovechamiento de los beneficios sociales de los países de acogida, especialmente los establecidos a favor de las personas mayores y los enfermos ${ }^{92}$. Solidaridad Democrática Española empezaba a ser considerado principalmente como un órgano de gestión enfocado a obtener ayudas de los organismos internacionales para sus damnificados.

\section{CONSIDERACIONES FINALES}

La necesidad de completar y complementar una organización formada por el PSOE, UGT y las JJSS con los instrumentos necesarios para desarrollar la solidaridad con los españoles, compatriotas afines a dichas organizaciones que vivían en condiciones extremas en el exilio, es el contexto en el que debemos situar el nacimiento en 1945 de Solidaridad Democrática Española en Francia.

91 Memoria de gestión del Comité Central presentada al VI Congreso de UGT, AFFLC, 864-005: 8.

92 Actas de las sesiones, agosto 1956. Ponencia de Solidaridad Democrática Española, AFFLC, 226-007: 9. 
UGT creció en el exterior de manera más rápida que el PSOE, tenía más secciones que el partido y mayor número de afiliados, por lo tanto, la aportación económica para Solidaridad se realizaba a través de la parte correspondiente de la cuota de los afiliados a la UGT. Pero estas cantidades eran insuficientes, por lo que los auxilios a los damnificados hubo que buscarlos fuera.

Las ayudas, directas o indirectas, llegaron de organismos internacionales oficiales y orientados de forma específica a los republicanos españoles o con un ámbito de actuación solidario más amplio, aunque también de entidades humanitarias de todo signo y de particulares.

SDE se extendió principalmente en Francia. El problema del elevado número de refugiados españoles establecidos en Francia tras la Guerra Civil, muchos de ellos alistados en sus unidades militares durante la Segunda Guerra Mundial, se agravó con la llegada de miles de clandestinos desde España a partir de 1945 y sobre todo en 1947. Sin embargo, en 1948 las autoridades francesas imponían una serie de medidas restrictivas para el establecimiento definitivo de nuevos exiliados en el país, política migratoria que tuvo su continuación de forma más drástica en la siguiente década.

Con un ámbito circunscrito fundamentalmente a Francia y África del norte, asistencia que también había hecho extensiva la organización benéfica a afiliados y familiares residentes en España, la actividad de SDE fue disminuyendo paulatinamente durante el transcurso de los años cincuenta. La actividad era inferior sobre todo porque el peso de los refugiados por cuestiones políticas se había reducido dentro de la colonia española, la coyuntura económica de España hizo que creciera el número de emigrados económicos entre los clandestinos conforme avanzaba la década, y por la ampliación de derechos sociales a los colectivos objeto de asistencia. Además, la asociación atravesaba también por graves problemas económicos.

La limitación de recursos obligó a destinarlos en la gestión de las ayudas. Los ingresos a través de las cuotas acabaron destinados en su totalidad al funcionamiento de la estructura de la organización. La afiliación fue en declive estos años y no se recuperaron los niveles de militancia a UGT, la organización de la que procedían las cuotas de solidaridad, ni con la llegada de la emigración española a Europa.

Solidaridad Democrática Española no tuvo los medios económicos y materiales de organismos similares pero consiguió un merecido reconocimiento internacional por la labor desarrollada con sus afiliados y con muchos otros españoles en este periodo, 1945-1956, los años de máxima actividad de la organización. 


\section{BIBLIOGRAFÍA}

Alted, Alicia, «La ayuda asistencial española y franco-española a los refugiados», en Alicia Alted y Lucienne Domergue (coords.), El exilio republicano español en Toulouse, 1936-1939, Madrid, UNED-PUM, 2003: 73-90.

Alted, Alicia, La voz de los vencidos, Madrid, Santillana Ediciones, 2005.

Botella Pastor, Virgilio, Entre memorias. Las finanzas del gobierno republicano español en el exilio, Madrid, Editorial Renacimiento, 2002.

Cervera Gil, Javier, «Su segunda posguerra. Los refugiados republicanos en el sur de Francia (1945-1947)», Espacio, Tiempo y Forma, Serie V, $H^{a}$ Contemporánea, 11 (Madrid, 1998): 191-211.

Dreyfus-Armand, Geneviève, «Los movimientos migratorios en el exilio», en Alicia Alted, y Lucienne Domergue, (coords.), El exilio republicano español en Toulouse, 1936-1939, Madrid, UNED-PUM, 2003: 29-52.

García, Julián, Emigrantes españoles. Episodios históricos, Talavera de la Reina, El autor, 2005.

Heine, Harmut, La oposición democrática al franquismo, 1939-1952, Barcelona, Editorial Crítica, 1983.

Martínez Cobo, Carlos y Martínez Cobo, José, La travesía del desierto: intrahistoria del PSOE (1954-1970), Barcelona, Plaza y Janes, 1989.

Mateos, Abdón, «Exiliados y presos políticos por la represión franquista en la posguerra. La solidaridad del socialismo español, 1944-1962», en Eduardo Ripoll y Manuel Ladero (eds.), Congreso Internacional Historia de los Pirineos, Madrid, UNED, 1991, tomo II: 411-426.

Mateos, Abdón, El PSOE contra Franco. Continuidad y renovación del socialismo español. 1953-1974, Madrid, Editorial Pablo Iglesias, 1993.

Mateos, Abdón, Exilio y clandestinidad. La reconstrucción de UGT, 1939-1977, Madrid, Ediciones Uned, 2002.

Mateos, Abdón, «El gobierno Negrín en el exilio: el Servicio de Evacuación de Refugiados», Historia del Presente, 10 (Madrid, 2007): 143-168.

Mateos, Abdón, La batalla de México: final de la Guerra Civil y ayuda a los refugiados, 1939-1945, Madrid, Alianza Editorial, 2009a.

Mateos, Abdón (ed.), ¡Ay de los vencidos!: el exilio y los países de acogida, Madrid, Eneida, 2009b.

Mateos, Abdón y Sánchez Andrés, Agustín (eds.), Ruptura y transición. España y México, 1939, Madrid, Eneida, 2011.

Pérez Fernández, Adolfo, La Comisión Socialista Asturiana. La oposición socialista al franquismo en el exilio: la importancia histórica de la Comisión Socialista Asturiana, 1942-1975, Madrid, Fundación Pablo Iglesias/Fundación José Barreiro, 1990.

Tcach, César y Reyes, Carmen, Clandestinidad y exilio: reorganización del sindicato socialista (1939-1953), Madrid, Editorial Pablo Iglesias/Fundación Francisco Largo Caballero, 1986. 
Velázquez, Aurelio, La otra cara del exilio: Los organismos de ayuda a los republicanos españoles en México (1939-1949), tesis doctoral, Salamanca, Universidad de Salamanca, 2012.

Velázquez, Aurelio, «La labor de solidaridad del gobierno Negrín en el exilio: el SERE (1939-1940)», Ayer: Revista de Historia Contemporánea, 97/1 (Madrid, 2015): 141-168.

Recibido: 19/12/2016

Aceptado: 29/05/2018 